\title{
POEMAS DE BEATRIZ SAAVEDRA GASTÉLUM ${ }^{1}$
}

\author{
Beatriz Saavedra Gastélum²
}

\section{Otras caras}

I

Es tan fácil lo real

abrir los rostros

como una rama seca

disfraz involuntario

Hay que ser cauteloso en las irradiaciones del espejo

reinventar la palabra

hundirse en ese manantial de humo

Apenas sinuosa

la noche derrama páginas para salvarme

soy mujer habitada por la luna

hierro ácido en mis huesos

II

El ojo aprende la música terrible

que el azar desvanece

${ }^{1}$ Fecha de recepción: 05/12/2015.

Fecha de aceptación: 20/12/2015.

${ }^{2}$ Escritora mejicana, asentada en la Ciudad de México, que ha publicado dos libros de poesía: Sueño obscuro que somos y Luz de otra sombra y ha sacado a la luz muchos poemas en diversas antologías: Disímbolos. Antología poética, XXI encuentro internacional de mujeres poetas, Segunda palabra. Antología literaria, La república en la voz de sus poetas, La poesía del encuentro.., y revistas: Revista de literatura Baquiana Miami, Revista de literatura Letralia, Revista literaria La Guillotina, Revista literaria Poemaria... Sus poemas se han traducido a distintas lenguas -francés, inglés, holandés, alemán y lenguas indígenas- y se han incluido en la Fonoteca Nacional como acervo del patrimonio cultural de la nación; $\triangle$ beatrizsaavedra@yahoo.com.mx. 
desemboca bajo el sol detenido

ausencia súbita que nace en la garganta

gota de luz

huella de escombro en los parajes

filtrada al centro de la muerte

\section{Antes de irte}

Puede ser que esté cansada

y los hilos del viento me desnuden

susurrando la llovizna de espectros

Acostumbrada al silencio

intimido al azar bajo la mesa

y me tumbo sobre tu sombra

para amortiguar mis golpes de incertidumbre

sobre la almohada quieta

de los años

\section{Realidad vacía}

I

Arrojo el tiempo que sobre mi sombra habita

Demasiado fuerte mi existencia oscura

Nadie conoce la mirada

las preguntas que importan

con su carga de espectros 
Sospechosa de la grandeza cotidiana

me he retirado

al Incendio voraz de angustia verdadera

a mi cuerpo de niña pálida

en las hendiduras secretas

para tocar la nada

los silencios de mi vientre

en la noche de humo

II

Entreabierta

en tus brazos fríos

mis muslos se desmayan

Este mendigar en los umbrales

y el miedo de lanzarme al vuelo

Tu propia luz sigue siendo llamarada

cerrando la boca de mi herida

involuntaria prófuga

de este infierno en agonía

\section{Cosas Vivas}

Dejo que en mi cuerpo todo se ilumine

Tacto de la memoria

Juventud inocente que busca la vida

experiencia y palabra

Disfraz del tiempo y sus apariciones 
la esencia intacta

el hundimiento de uno mismo

Fondo de un mundo desconocido

que no tiene rostro

Voz encantada idéntica a mi piel

$\mathrm{Y}$ en su metamorfosis

me reinvento

\section{Guerrera}

I

Temporal de pensamiento

me vuelve quebrantable

Tu voz de pájaros

anuda cada gota de la noche

Quiero abrirte el corazón

que mi fiebre de huracán avance

entre tus labios

con tu nombre espectral en el espejo

II

Mujer en la humedad de la tierra

piedra caída

sol en el pecho

gota tenaz

que llena mis ojos de aguas y de mieles

ojos siempre despiertos

para liberar vida

con la conciencia y el candor del mundo 


\section{No me reconocieron los espejos}

I

Tocamos feroces la sombra de un rostro

En vano su goce perdido

piel traslúcida de viento

que se tiende inacabada

Los dioses son formas quiméricas

con manos desnudas tocan el vacío

La verdadera vida

atenta contra la noche

Es golfo de luz

piel vulnerable de mujer apenas

Más allá de la infancia

Tras vidrieras pesadas de silencios

enfrentamos a la muerte

II

La noche se agota en polvo de sangre

ficticias contusiones

péndulo de fantasía

Hay que soñar para saberse vivo

sufrir caídas insondables

ser realidad de otros nombres

aire en la frente

labios de hilo último 
grietas del primer pecado

Las palabras son apariciones

a punto de nombrar la vida

el árbol

el tiempo

A veces última puerta

A voces de incendio

Erosiones de tierra infértil

III

Soy la circunstancia

Sostengo la vida

Fuera de mí no veo

sino esta realidad

No hay hora en que amanezca

a un mar infinito

Tendemos las redes

los cuerpos intangibles

para hundir el sonido

hálito en las manos

donde la puerta impasible

me abrace a puño cerrado

IV

Miro la noche prematura

de mi propio cuerpo 
Punto inerte de presencias vanas

oscila la eternidad

en los laberintos nublados de mi ceguera

Existir en otra parte

los universos son murmullo

aliento nuevo

abismo

silencio congelado donde empieza el día

gira el espacio sobre nuestros cuerpos

El límite olvida tu presencia

busco mi centro en el túnel de sombras

para inventar el estallido de palabras

donde el aire esgrime

y renazco. 